\title{
Science Education and Mobile Learning: A Content Analysis Review of the Web of Science Database
}

\author{
https://doi.org/10.3991/ijet.v14i22.11744 \\ Metin Odabasi $(\bowtie)$ \\ Eastern Mediterranean University, Famagusta, North Cyprus via Mersin 10, Turkey \\ mbodabasi9@gmail.com \\ Huseyin Uzunboylu \\ Near East University, Nicosia, North Cyprus via Mersin 10, Turkey \\ Olga V. Popova \\ Financial University under the Government of the Russian Federation, \\ Moscow, Russia \\ Nikolay N. Kosarenko \\ Plekhanov Russian University of Economics, Moscow, Russia \\ Izida I. Ishmuradova \\ Kazan (Volga region) Federal University, Kazan, Russia
}

\begin{abstract}
The use of mobile technologies in education has appealed considerable interest and attention from educators and researchers in the last decade. Nonetheless, the effects of mobile learning on students' learning outcome in science education are still ambiguous. The time and place flexibility, ubiquity and easy accessibility of mobile devices are among the features that make them valuable in m-learning, especially in science education, at present times. Despite the large number of researches conducted, no bibliometrics study has been carried out in this topic so far. The aim of this review is to assess the progress of international publications in the area of science education and mobile learning. This content analysis review shows the trends in publications regarding mobile learning and science education researches indexed in Web of Science database between years 2004-2019. Out of 57 documents related to the topic of interest found in the database of Web of Science, the results demonstrate that the publication frequency has increased after 2012 where the most productive year was 2016. Most of the published documents were proceedings papers and original articles. Taiwan and United States are the countries with most work published where $\mathrm{Pa}$ kistan, Taiwan and China are the countries that funded the most scientific research. The top journal involving the publications associated with this topic is Computers \& Education journal. A more comprehensive criteria has been used in this content analysis which has interpreted in detail. This study can provide a much clear picture of the field to researchers, educational leaders and funders to incorporate new understandings into their research.
\end{abstract}


Keywords - Science education, mobile learning, content analysis, educational technology

\section{Introduction}

Technological innovations are influencing every aspect of our lives and the continuous advances in technology is changing the way we learn. As the popularity of mobile devices increases, their connection with our day-to-day life increases. Different innovative features are continually optimizing our lives and making them easier as they become available with every new version of mobile devices. Together with the advancing technology, education has also encountered several developments [1]. Many educators and researchers have been encouraged by these advances to employ mobile devices in order to improve teaching and learning [2]. There is a great potential in utilizing mobile technologies to change the way students learn by transforming a conventional classroom to one that is more engaging and interactive [2]. It provides educators the ability to teach without the restriction of time and place, allowing learning environment to extend beyond classroom and the school time [3]. This grants educators the ability to bond with students on a more personal level with the devices they use on a daily basis hence making learning more personalised and customised [4].

The fast development in the technology world has created multiple new ways to understand ubiquitous learning [5]. This has induced a new concept into the distance learning area; mobile learning (m-learning) which can be defined as "learning through content and social interactions across multiple contexts using personal mobile devices" [6]. Given the widely adopted use of mobile devices in the field of education, the research and studies on m-learning is fast increasing [7][8]. Therefore, with the raised interest in mobile learning over the last 10 years, dedicated literature reviews have been carried out in several studies with the purpose to apprehend certain aspects of the field [9][10][11]. In this past decade, a substantial amount of initiatives has been initiated with the objective to use mobile technologies and applications for educational purposes. For example, some studies focused on mobile learning games and apps [2][12][13] while others focused on computer aided collaborative m-learning [14]. Each research has contributed significant information for academics to improve the understanding on the use of mobile technologies in educational context [15].

Latest technologies, especially mobile devices, hold the potential to revolutionize teaching and learning in science [16]. The practice of science learning usually follows investigative approaches, which incorporate open-inquiry methods that are underpinned by socio-cultural theory and social constructivism [17][18][19]. Granted that mobile learning in science through mobile devices fit well within the socio-cultural perceptions and the framework of pedagogical affordances of m-learning which are classified as personalisation, authenticity and collaboration [18][20], it is of interest to explore the research that has been done about their use in science learning. In science education, blending technology with education can bridge scientific environment and learning in classroom. M-learning can offer a more realistic framework for lab-based investigation or form an informal and personal learning episode "in situ" that can be 
used as a resource to incorporate as formal learning in schools [18]. Mobile devices might mediate and help reshape the boundaries between the contexts of formal and informal learning [21]. Digital technologies in the classroom have been encouraged in science as part of an information delivery system to promote active learning and knowledge construction for several purposes, from instructional delivery tools to learners' presentations, communication and research [18][22][23]. Merging technology with education is quite important to improve learning more and it is also necessary to support it by developing creative solutions with new technological innovations, which should be assessed regularly on how valuable and constructive technology is for education [24][25].

Even though there has been numerous research synthesis of some valuable studies on mobile learning, some areas still require further exploration. For instance, the solid potential of exploiting mobile learning in science education should be examined more due to various facets that make it quite suitable to the affordances of mobile technology [2]. There is no doubt that most of the science content happens outside the class and perhaps can be better understand when studied in its "in situ" in other words, its natural environment, while the remainder of the science content is quite hard to observe with the bare eye and needs graphical visualisations for the learners to be able to comprehend the subject fully. Furthermore, a deeply engaging experience is required to completely understand scientific system models that demonstrates the interaction between variables.

With the abilities equipped by the newer devices, such as to display and demonstrate interactive, three dimensional (3D) visuals and simulations, the unique aspects of science learning are far better supported [2]. Nevertheless, there have been very few reviews of research carried out regarding mobile learning in science on the Web of Science database to date, let alone any reviews of the content analysis. Therefore, an extensive content analysis of the findings are required in order to better understand the researches carried out regarding the mutual relationships between science education and mobile learning. The aim of this study is to conduct a review of the published work on mobile learning in science education including biology, chemistry and physics education. This work would assist educators and researchers to enhance the comprehension of the ways in which m-learning is being used in science education. The information collected from reviews would enable them to evaluate their own methods of teaching in the light of content analysis concerning the research conducted on the usage of mobile devices in science education and would allow them to build and integrate their novel ideas into their own work. This analysis would also be in benefit for the funders, policy makers and educational leaders as well as researchers and teachers as the extent of studies to date in the relevant topic are analysed and clarified. The results can help in making arrangements to support further research and help allocate the necessary resources.

The researchers reviewed the Web of Science database as a way of analysing the work published that has been carried out so far to gain an understanding of the scope of the research activity in the use of mobile learning in science. This will provide an extensive and reliable picture of the topic being reviewed [26]. This review was guided 
with the primary question, what research has been published regarding the use of mobile learning in science education from 2004 to 2019 on the Web of Science database?

\section{$2 \quad$ Method}

\subsection{Research model}

The research model used in this review is content analysis which is amongst the most frequently used qualitative research methods. The purpose of using this method is to reveal the facts behind the historical and current situation of the field of interest and provide more clarity for the data collected through this bibliometrics analysis.

\subsection{Data collection}

The data of the study were obtained by searching Web of Science database covering articles published from 2004 to 2019. The data base was searched with the keywords "science education" and "mobile learning". However, related terms were used in order to create a more comprehensive review such as "biology education", "chemistry education" and "physics education", but the results showed the same documents. The figure below shows the search page of Web of Science for our topic.

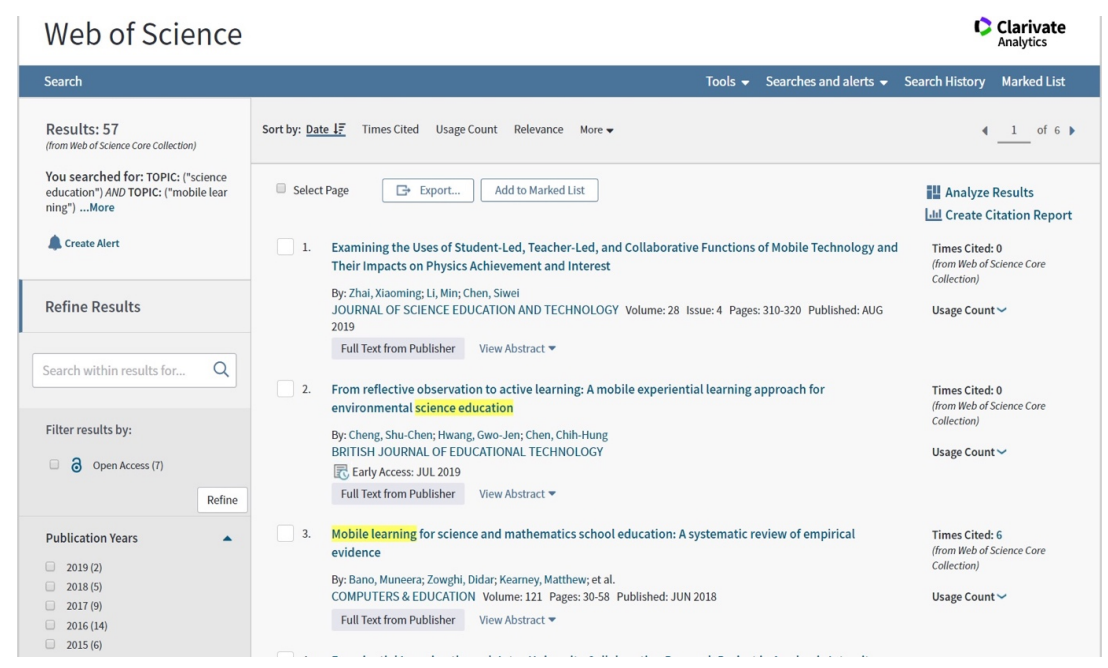

Fig. 1. Science Education and Mobile Learning search page

\subsection{Data analysis}

In the data analysis part, a criteria for the content analysis was determined to review the documents published. This criteria includes: 
- Year of publication

- Type of documents

- Funding agencies

- Authors

- Source titles

- Research area

- Countries

- Language

- Organizations

\section{$3 \quad$ Results}

The results were analyzed and interpreted under 9 different categories based on a total number of 78 published documents obtained from Web of Science database. The evaluation has been made according to the criteria-based content analysis where the relevant literature research has been undertaken to discuss the data.

\subsection{Trends in the published documents based on the publication year}

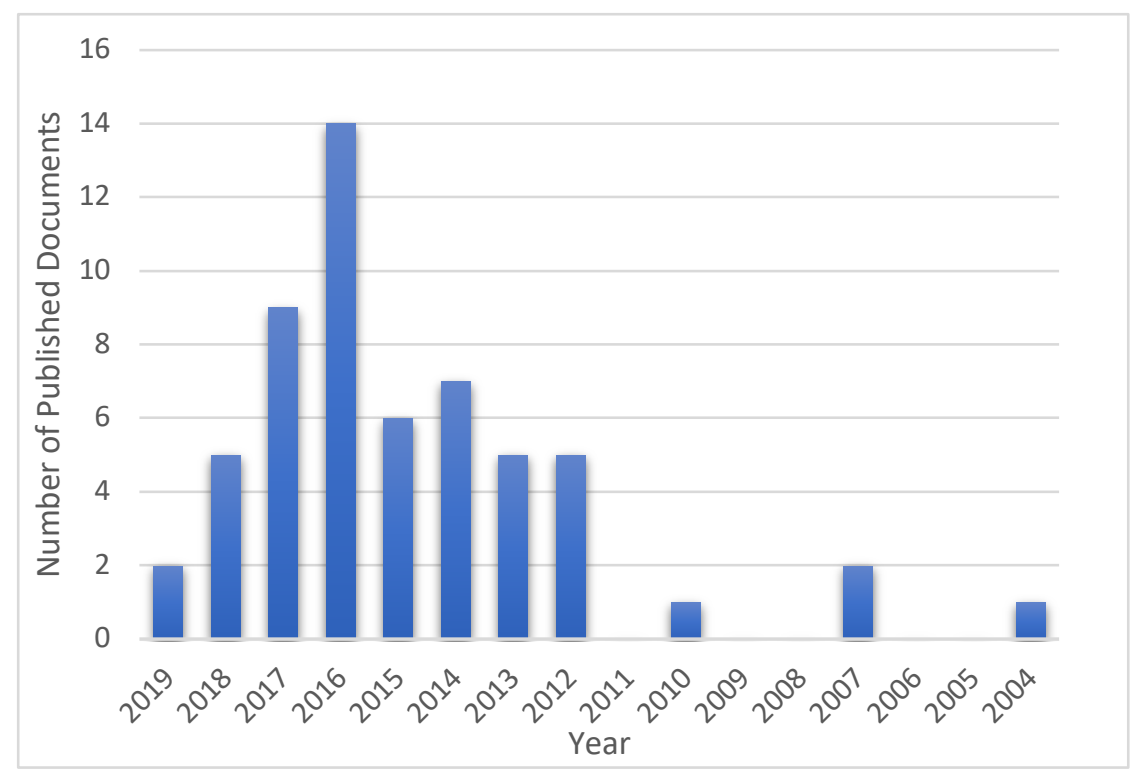

Fig. 2. Distribution of the Published Documents between years 2004-2019

The Figure 2 illustrates the distribution of the published documents on science education and mobile learning including the subject areas biology, chemistry and physics between the years 2004-2019 based on Web of Science database. As It can be seen from the figure above that there were not many publications in this subject from 2004 to 2011 
where the total number of publications made within this 8 year period is only 4 ( 1 in 2004, 2 in 2007 and 1 in 2010). There were no publications in 2005, 2006, 2008, 2009 and 2011. However, following 2012 the number of publications increases gradually where the number of documents published peaks in 2016 with 14 publications.

\subsection{Assessment of the published documents based on the type of document}

Table 1. Distribution of the number of documents published based on the type of document

\begin{tabular}{|l|c|c|}
\hline \multicolumn{1}{|c|}{ Document Type } & No. of Documents & \% \\
\hline Proceedings Paper & 31 & 54.39 \\
\hline Article & 24 & 42.11 \\
\hline Review & 3 & 5.26 \\
\hline Book Chapter & 2 & 3.51 \\
\hline Early Access & 1 & 1.75 \\
\hline Total & $\mathbf{6 1}$ & $\mathbf{1 0 0}$ \\
\hline
\end{tabular}

As the Table 1 shows, more than half of the published work consist of proceedings papers with 31 documents out 61 documents (54.39\%), followed by 24 articles making up $42.11 \%$ of the documents published. Therefore, it can be said that the preferred publication types for authors is proceedings papers and research articles compared to other forms of documents (i.e. review, book chapter or early access).

\subsection{Assessment of the published documents supported by funding agencies}

Table 2. Distribution of the published scientific documents sponsored by funding agencies

\begin{tabular}{|l|l|l|}
\hline \multicolumn{1}{|c|}{ Funding Agencies } & No. & $\%$ \\
\hline Higher Education Commission Pakistan & 2 & $3.51 \%$ \\
\hline Aim for The Top University Project At The National Taiwan Normal University & 2 & $3.51 \%$ \\
\hline Australian Research Council & 1 & $1.75 \%$ \\
\hline California Discovery Grant (US) & 1 & $1.75 \%$ \\
\hline Chinese Scholarship Council & 1 & $1.75 \%$ \\
\hline $\begin{array}{l}\text { Committee on Research And Development of The Education University Of Hong } \\
\text { Kong }\end{array}$ & 1 & $1.75 \%$ \\
\hline E-campus Ontario (Canada) & 1 & $1.75 \%$ \\
\hline European Union (EU) & 1 & $1.75 \%$ \\
\hline $\begin{array}{l}\text { FEDER Funds through the Compete Operational Programme for Competitiveness and } \\
\text { Internationalisation (POCI) }\end{array}$ & 1 & $1.75 \%$ \\
\hline
\end{tabular}

The Table 2 shows the number of published scientific documents that was sponsored by funding agencies. The most scientific work was funded by Higher Education Commission (HEC) Pakistan and Taiwan's Aim for the Top University Program where each institution funded 2 research work comprising $3.51 \%$ of the documents. The rest of the institutions displayed were only funded 1 research work in the relevant subject area so far. There are 28 more different funding agencies which were not displayed in the table. Furthermore, 36 records $(63.158 \%)$ do not have any data in the field being analyzed. 


\subsection{Assessment of the published documents based on authors}

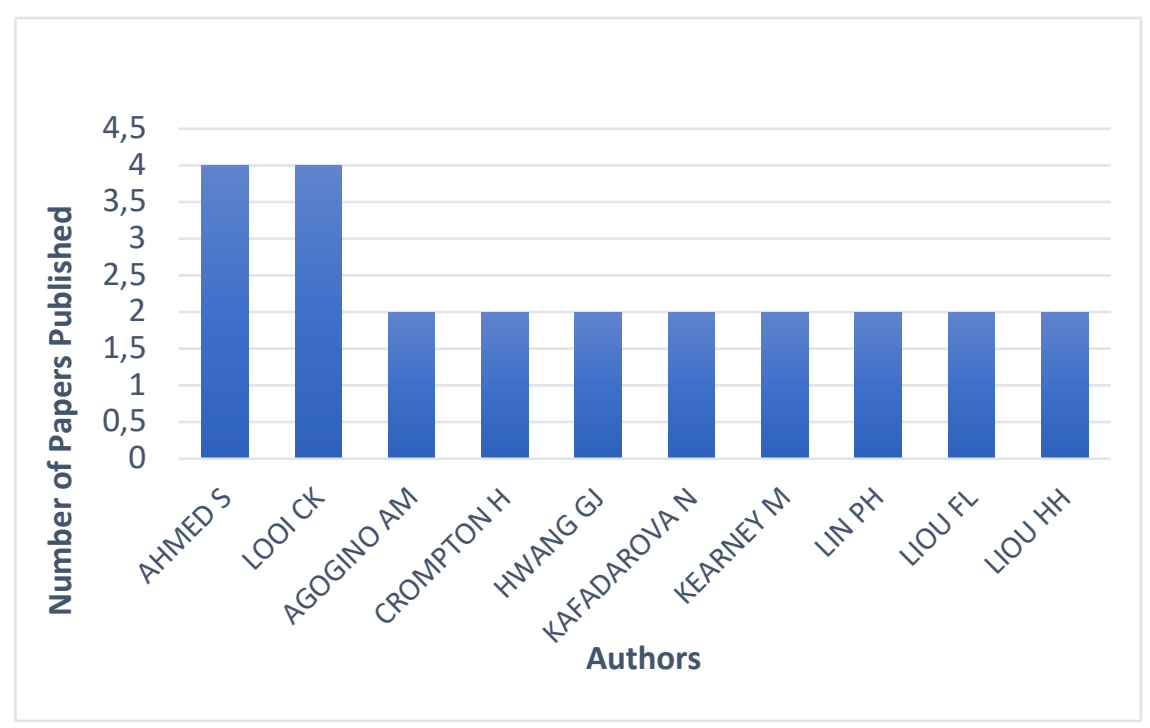

Fig. 3. Distribution of the published documents based on authors

Figure 3 represents the top 10 authors who has significant work published in the subject area where 154 Authors has value(s) outside the display options. It can be seen that the most work has been published by the authors Ahmed S. and Looi C. K. with each author having 4 publications in the relevant subject area. However, the trend remains constant when looked at the other authors.

\subsection{Assessment of the published documents based on source titles}

Table 3. Distribution of the published documents based on the source titles

\begin{tabular}{|l|c|c|}
\hline \multicolumn{1}{|c|}{ Source Titles } & Record Count & $\mathbf{\%}$ \\
\hline Computers \& Education & 6 & $10.53 \%$ \\
\hline INTED Proceedings & 4 & $7.02 \%$ \\
\hline International Educational Technology Conference & 3 & $5.26 \%$ \\
\hline Lecture Notes in Computer Science & 3 & $5.26 \%$ \\
\hline Procedia Social and Behavioral Sciences & 3 & $5.26 \%$ \\
\hline Communications in Computer and Information Science & 2 & $3.51 \%$ \\
\hline EDULEARN Proceedings & 2 & $3.51 \%$ \\
\hline Frontiers In Education Conference & 2 & $3.51 \%$ \\
\hline IEEE Global Engineering Education Conference & 2 & $3.51 \%$ \\
\hline Others & 30 & $52.63 \%$ \\
\hline
\end{tabular}

The top 10 source titles associated with the topic of science education and mobile learning obtained from the Webs of Science database is shown in Table 3. The other 49 source title values are outside of the display option. It can be seen from the figure that most research work has been published in the Computers \& Education Journal 
comprising $10.53 \%$ of the data. The result is then followed by International Technology Education and Development Conference (INTED) Proceedings with 4 publications $(7.02 \%)$.

\subsection{Distribution of the published documents based on the countries}

Distribution of the top 10 countries by the number of published scientific papers in Web of Science database is shown in the Figure 4. The data for 18 other countries which have published scientific work associated with the subject is not displayed as all the other countries have only 1 published document. According to the figure, the results illustrate that USA and Taiwan are the top 2 countries with the most scientific work conducted and published in science education and mobile learning area with 9 publications in each country. China, Singapore, Canada, Greece, Malaysia and Pakistan are among the countries with high number of publications. Hence, it can be seen from the chart that Asia is the region with the highest number of published documents in the field analysed.

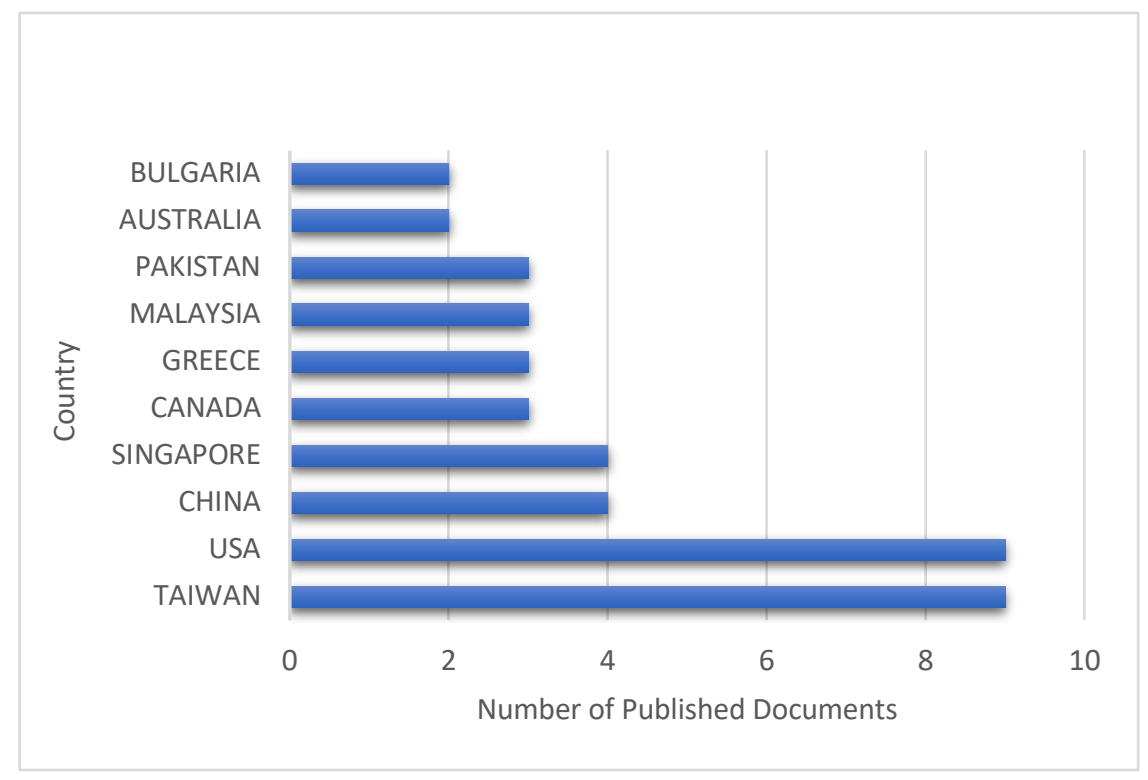

Fig. 4. Distribution of the number published documents based on the countries

\subsection{Distribution of the published documents based on the language}

All the documents found in the Web of Science database associated with the subject of interest "science education and mobile learning" are in English. There weren't any other documents published in any other languages. 


\subsection{Distribution of the published documents based on the research area}

\section{Number of Documents Published in Different}

2211 Research Areas

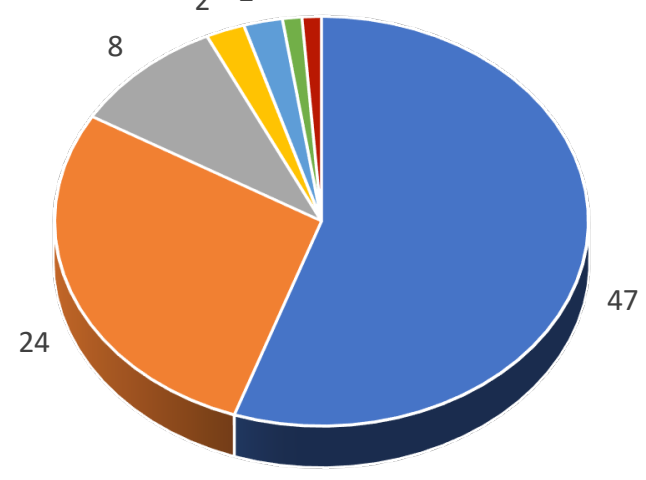

- EDUCATION/EDUCATIONAL

RESEARCH

- COMPUTER SCIENCE

- ENGINEERING

- TELECOMMUNICATIONS

- SCIENCE TECHNOLOGY

- BIOCHEMISTRY \&

MOLECULAR BIOLOGY

- CHEMISTRY

Fig. 5. Pie chart representing the distribution of the published documents based on the research area

The amount of scientific work carried out in different fields of research has been investigated within the scope of this research from the database of Web of Science and the results are displayed in Figure 5.

As the results indicate, the most publication regarding mobile learning in science education is carried out in the research area of Education/Educational Research with 47 published scientific papers.

This is followed by 24 published documents in Computer Science. However, the frequency of publication is very minor in the Life Sciences field including Chemistry, Biology, Biochemistry, Molecular Biology and etc. 


\subsection{Distribution of the published documents based on the organisation}

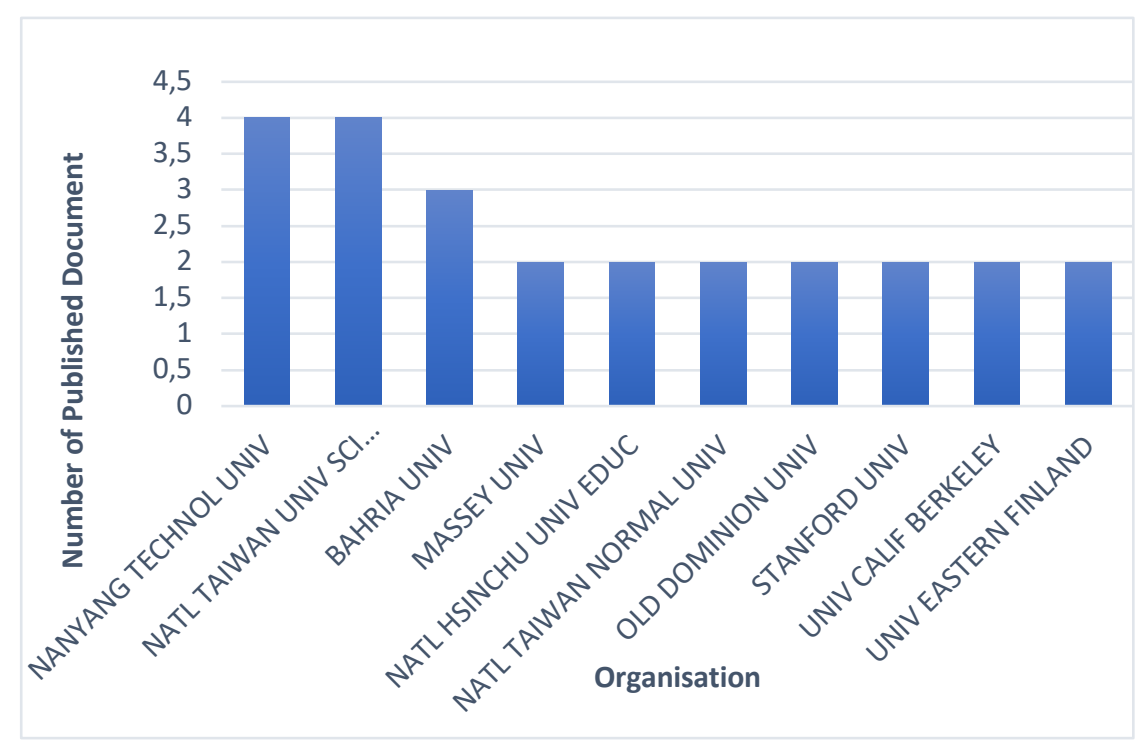

Fig. 6. Distribution of the published documents based on the organisation

The Figure 6 shows the distribution of the amount of scientific documents published as regards to the organisation. 60 organisations not included in the display due to insignificant publication frequency. The top 2 organisations with the most number of publications in this subject area are National Taiwan University of Science and Technology and Nanyang Technological University, each university having 4 publications. The publication frequency is then followed by Bahria University with 3 publications.

\section{Discussion}

This review examined the studies concerning mobile learning in science education published in Web of Science between the years 2004-2019 to show the rate of interest in mobile science learning and how many studies have been conducted to help understand the educational necessities needed in this area. With the mobile technologies developed, it has become much more easier to show examples that were impossible to demonstrate in the classroom to the students [27][28]. This work can provide an up-todate analysis for future researchers to build on and reference their work and put more to the knowledge about science education and mobile learning.

According to the Figure 2, The publication frequency on the topic mobile science education including biology, chemistry and physics education has increased following 2012 as the interest in mobile learning area increases day by day with advancing technologies where the highest number of documents published is in 2016 with 14 publications. This might be due to the fact that mobile learning has become more accessible for learners all over the world [29][30]. Moreover, interest of educational researchers 
in more progressive mobile pedagogical approaches may have influenced researchers to conduct studies in which more authentic and social approaches were used [19].

The results show that the most published document types in the field of mobile learning in science education are proceedings papers and research articles compared to reviews and other forms of documents. This indicates that there hasn't been much synthesis of the researches that has been done in this particular area to reflect the understandings regarding the use of mobile technologies in science education which can be useful to enable new understandings or new concepts of the data to arise. Although, useful and novel ideas can be gained from both proceedings and journal articles, reviews can ensure findings from original studies to contribute to a superior understanding of the area.

Leading countries have the potential and research capabilities to greatly influence future directions in principal scientific fields by identifying and supporting emerging topics. Moreover, research areas financed by the leading countries in scientific research not only influence the research interests of investors and scientists but also direct funding priorities of other developing countries [31]. The funds provided by top 3 leading countries in scientific research, the US, China and Germany [32], has even more influence. Publications supported financially by these countries appear more frequently in esteemed journals which naturally receives more attention and generates more recognition [31]. The most scientific research published sponsored by funding agencies belong to Pakistan, Taiwan and China. Therefore, more of these leading countries should fund research regarding mobile learning in science education. With more work supported by funding agencies, more research can be initiated in this area. With that being said, the United States and Taiwan appear to have the most scientific work conducted and published in the area of mobile learning and science education followed by China and Singapore. A relatively small amount of countries were responsible for the most research published mainly in the Asia region. It also appears that the topic of science education through mobile learning is not under the attention of European countries. Even though there are researchers and authors contributing studies from all around the world, there is not any established author specialised in this topic as the analysis results of the published documents based on authors are very persistent, in which most authors having maximum amount of two papers in this field.

Even though most research regarding the topic have been conducted in countries whose main language is not English, all the papers published are in English which show the importance of international recognition and to reach a bigger academic audience. This can also be interpreted as, publication metrics hence publication in prestigious indexes, such as the Science Citation Index (WoS) in which $2 / 3$ of the journals included publish in English, are key measures for global rankings of universities [33]. When looked at the sources of the published documents, where the researches related to our topic of interest have issued, it can be seen that the most of the studies have been published on platforms that promote international education in the field of technology and science to increase the knowledge on digital technology to improve education. Among the top 10 sources, Computers \& Education journal has the lead with 6 published articles. However, majority of the studies were not published in high quality and high impact international journals but rather they have been published as conference 
proceedings which does not attract much worldwide attention to the topic. Education/Educational research was the leading subject area among the published documents followed by Computer Science which refers to the interests of using technological innovations as a novel way to improve learning in education through mobile devices. There is considerable interest from educators and technical developers in exploiting the unique capabilities and characteristics of mobile technologies to enable new and engaging forms of learning. The leading organisations that contribute to the research publication in this field are National Taiwan University of Science and Technology and Nanyang Technological University. For example, Nanyang Technological University offers grants to encourage research projects on technological based innovative strategies aiming to improve student learning [34].

\section{Conclusion}

Researches published in Web of Science database between 2004-2019 have been screened. Looking at the results as a whole, it can be said that there is an escalating interest in using mobile devices in science education. The results showed an ascending trend in international publications on researches associated with mobile learning and science education. The trend was in line with the development of novel technologies in mobile learning and its transformation to use it for the improvement of students' learning outcome in science education including the fundamental branches biology, chemistry and physics. The majority of the research published are articles and proceedings, with quite low amount of reviews where Taiwan and the United States are among the top countries with the most published work. An interesting observation was that there wasn't much attention from European countries on the topic of science education via mobile learning. Such comprehensive picture of the topic can be valuable for researchers, educational leaders, funders and policy makers as these analyses can provide an insight into the recent publication activity. However, this study was only limited to the database of Web of Science so further research has to be carried out to analyse the other academic databases. Furthermore, other content analysis criteria should be included in future research involving sample groups, research method, mobile devices used and citation number.

\section{References}

[1] Sürmelioğlu, Y., \& Seferoğlu, S. (2019). An examination of digital footprint awareness and digital experiences of higher education students. World Journal on Educational Technology: Current Issues, 11(1), 48-64. https://doi.org/10.18844/wjet.v11i1.4009

[2] Zydney, J. M. and Warner, Z. (2016) 'Mobile apps for science learning: Review of research', Computers \& Education, 94, pp. 1-17. https://doi.org/10.1016/j.compedu.2015.11.001

[3] Huang, Y.-M., Lin, Y.-T. and Cheng, S.-C. (2010) 'Effectiveness of a Mobile Plant Learning System in a science curriculum in Taiwanese elementary education', Computers \& Education, 54(1), pp. 47-58. https://doi.org/10.1016/j.compedu.2009.07.006 
Paper-Science Education and Mobile Learning: A Content Analysis Review of the Web of Science...

[4] Chu, H.-C. et al. (2010) 'A two-tier test approach to developing location-aware mobile learning systems for natural science courses', Computers \& Education, 55(4), pp. 1618-1627. https://doi.org/10.1016/i.compedu.2010.07.004

[5] Yakubu, M., Hassan, A., Ahmad, A., Musa, K., \& Gital, A. (2018). Mobile learning stimulus in Nigeria. Global Journal of Information Technology: Emerging Technologies, 8(3), 95101. https://doi.org/10.18844/gjit.v8i3.4049

[6] Crompton, H. (2013) 'A Historical Overview of M-Learning', in Handbook of Mobile Learning. Routledge, p. 4. https://doi.org/10.4324/9780203118764.ch1

[7] Keser, H., \& Semerci, A. (2019). Technology trends, Education 4.0 and beyond. Contemporary Educational Researches Journal, 9(3), 39-49. https://doi.org/10.18844/cerj.v9i3.4269

[8] Stan, E. (2019). Mobile learning in Romania, a failed experience?.New Trends and Issues Proceedings on Humanities and Social Sciences, 6(1), 296-303. https://doi.org/10.18844/ prosoc.v6i1.4181

[9] Hwang, G.-J. and Tsai, C.-C. (2011) 'Research trends in mobile and ubiquitous learning: a review of publications in selected journals from 2001 to 2010', British Journal of Educational Technology. John Wiley \& Sons, Ltd (10.1111), 42(4), pp. E65-E70. https://doi.org/10.1111/j.1467-8535.2011.01183.x

[10] Hung, J.-L. and Zhang, K. (2012) 'Examining mobile learning trends 2003-2008: a categorical meta-trend analysis using text mining techniques', Journal of Computing in Higher Education. Springer US, 24(1), pp. 1-17. https://doi.org/10.1007/s12528-011-9044-9

[11] Wu, W.-H. et al. (2012) 'Review of trends from mobile learning studies: A meta-analysis', Computers \& Education. Pergamon, 59(2), pp. 817-827. doi: 10.1016/J.COMPEDU.2012. 03.016.

[12] Jeng, Y.-L. et al. (2010) The Add-on Impact of Mobile Applications in Learning Strategies: A Review Study, Educational Technology \& Society. Available at: https://pdfs.semanticscholar.org/fc01/25a52aa31aea61621593c60493cca9abflad.pdf (Accessed: 14 August 2019).

[13] Schmitz, B., Klemke, R. and Specht, M. (2012) 'Effects of mobile gaming patterns on learning outcomes: a literature review', International Journal of Technology Enhanced Learning, 4(5/6), p. 345. https://doi.org/10.1504/ijtel.2012.051817

[14] Hsu, Y.-C. and Ching, Y.-H. (2013) 'Mobile computer-supported collaborative learning: A review of experimental research', British Journal of Educational Technology. John Wiley \& Sons, Ltd (10.1111), 44(5), pp. E111-E114. https://doi.org/10.1111/bjet.12002

[15] Crompton, H. and Burke, D. (2018) 'The use of mobile learning in higher education: A systematic review', Computers \& Education, 123, pp. 53-64. https://doi.org/10.1016/j. compedu.2018.04.007

[16] Metz, S. (2014) 'Editor's Corner: Science Teaching and Learning in the 21st Century', The Science Teacher, 081(06). https://doi.org/10.2505/4/tst14 $08106 \quad 6$

[17] Salomon, G. and Perkins, D. N. (1998) 'Chapter 1: Individual and Social Aspects of Learning', Review of Research in Education. Sage PublicationsSage CA: Thousand Oaks, CA, 23(1), pp. 1-24. doi: 10.3102/0091732X023001001.

[18] Burden, K. and Kearney, M. (2016) 'Future Scenarios for Mobile Science Learning', Research in Science Education, 46(2), pp. 287-308. https://doi.org/10.1007/s11165-016-95141

[19] Bano, M. et al. (2018) 'Mobile learning for science and mathematics school education: A systematic review of empirical evidence', Computers \& Education, 121, pp. 30-58. https://doi.org/10.1016/j.compedu.2018.02.006

[20] Kearney, M. et al. (2012) 'Viewing mobile learning from a pedagogical perspective', Research in Learning Technology, 20(1), p. 14406. https://doi.org/10.3402/rlt.v20i0.14406 
[21] Lai, K.-W., Khaddage, F. and Knezek, G. (2013) 'Blending student technology experiences in formal and informal learning', Journal of Computer Assisted Learning, 29(5), pp. 414425. https://doi.org/10.1111/jcal.12030

[22] Kirkman, P. (Cambridge A. I. E. (2017) Digital technologies in the classroom. Available at: https://www.cambridgeinternational.org/Images/271191-digital-technologies-in-the-classroom.pdf (Accessed: 13 August 2019).

[23] Sarican, G., \& Akgunduz, D. (2018). The impact of integrated STEM education on academic achievement, reflective thinking skills towards problem solving and permanence in learning in science education. Cypriot Journal of Educational Sciences, 13(1), 94-113. https://doi.org/10.18844/cjes.v13i1.3372

[24] Soykan, E. and Ozdamli, F. (2016) 'The Impact of M-Learning Activities on the IT Success and M-Learning Capabilities of the Special Education Teacher Candidates', World Journal on Educational Technology: Current Issues, 8(3), p. 267. https://doi.org/10.18844/ wjet.v8i3.1019

[25] Devedzic, V., \& Devedzic, M. (2019). Technology-Enhanced Assessment at universities and in schools: An initiative. International Journal of Learning and Teaching, 11(3), 89-98. https://doi.org/10.18844/ijlt.v11i3.4319

[26] Gough, D. (David A, Oliver, S. and Thomas, J. (2012) An introduction to systematic reviews.

[27] Su, C.-H. and Cheng, C.-H. (2013) 'A Mobile Game-based Insect Learning System for Improving the Learning Achievements', Procedia - Social and Behavioral Sciences. Elsevier, 103, pp. 42-50. https://doi.org/10.1016/j.sbspro.2013.10.305.

[28] Soykan, E. and Uzunboylu, H. (2015) 'New trends on mobile learning area: The review of published articles on mobile learning in science direct database', World Journal on Educational Technology, 7(1), p. 31. https://doi.org/10.18844/wjet.v7il.22

[29] Bukharaev, N. and Wisam Altaher, A. (2017) 'Mobile Learning Education has Become More Accessible', American Journal of Computer Science and Information Technology. iMedPub, 05(02). https://doi.org/10.21767/2349-3917.100005

[30] NetNewsLedger (2019) Why mobile learning is the future of education on the go, NetNewsLedger. Available at: http://www.netnewsledger.com/2019/06/25/why-mobile-learning-isthe-future-of-education-on-the-go/ (Accessed: 17 August 2019)

[31] Wang, J. and Shapira, P. (2015) 'Is there a relationship between research sponsorship and publication impact? An analysis of funding acknowledgments in nanotechnology papers.', PloS one. Public Library of Science, 10(2), p. e0117727. https://doi.org/10.1371/journal.pone. 0117727

[32] Natureindex.com. (2019). The top 10 countries for scientific research in 2018. [online] Available at: https://www.natureindex.com/news-blog/top-ten-countries-research-sciencetwenty-nineteen [Accessed 26 Aug. 2019]

[33] Curry, M. J. and Lillis, T. (2018) The Dangers of English as Lingua Franca of Journals. Available at: https://www.insidehighered.com/views/2018/03/13/domination-english-language-journal-publishing-hurting-scholarship-many-countries (Accessed: 19 August 2019)

[34] Ntu.edu.sg. (2019). EdeX Grants. [online] Available at: http://www.ntu.edu.sg/tlpd/GrantsandAwards/EdexGrants/Pages/index.aspx [Accessed 26 Aug. 2019] 


\section{$7 \quad$ Authors}

Metin Odabasi graduated from University of Sussex, completing a degree in BSc Biochemistry in 2017 and graduated from University of Warwick, completing a degree in MSc Biotechnology, Bioprocessing and Business Management in 2018. Currently, doing his $\mathrm{PhD}$ in Chemistry in Eastern Mediterranean University and working as a Science Teacher at Levent College, Cyprus.

Huseyin Uzunboylu graduated from Anadolu University, completing a degree in BSc Educational Communicating and Planning in 1991. He graduated from Ankara University; completed a degree in MA Curriculum and Instruction in 1995 and completed PhD in area of Educational Technology in 2002. He became Assistant Professor in 2013, Associate Professor in 2015 and Professor of Educational Technology in 2010 at Cyprus Near East University. Email: huseyin.uzunboylu@gmail.com

Olga V. Popova is PhD in Law, Associate Professor of the Department of Legal Regulation of Economic Activity at Financial University under the Government of the Russian Federation (49 Leningradsky prospect, 125993, Moscow, Russia). She has more than 50 published scientific works in Russian and international journals, indexed by Scopus and Web of Science data bases. Her research interests are connected with educational environment problems, educational technologies and economic effectiveness of educational system. E-mail: helga-popova@yandex.ru

Nikolay N. Kosarenko is $\mathrm{PhD}$ in Law and $\mathrm{PhD}$ in Philosophy, Associate Professor of the Department of State Legal and Criminal Law Disciplines at Plekhanov Russian University of Economics (36 Stremyannyi Pereulok, 115093, Moscow, Russia). He is a well-known Russian scientist and has a lot of published articles in Russian and International journals on the problems of law, philosophy and history of Russian law. He is also interested on the problems of philosophy of education, educational environment, scientific methodology. E-mail: nkosarenko@yandex.ru

Izida I. Ishmuradova is $\mathrm{PhD}$ in Economics, Senior Lecturer of the Department of Business Informatics and Mathematical Methods at Kazan (Volga region) Federal University (Naberezhnye Chelny Institute - Branch) (18 Kremlyovskaya Street, 420000, Kazan, Russia). Her research interests are connected with innovations, computer science, mathematics, social sciences, economics, econometrics and finance, business, management and accounting, arts and humanities, environmental science, energy, engineering. E-mail: iiishmuradova@kpfu.ru

Article submitted 2019-09-23. Resubmitted 2019-10-20. Final acceptance 2019-10-21. Final version published as submitted by the authors. 